with MV disease based on basic physiological aspects of the left ventricle secondary to the diastolic overload. We do not have good data regarding the impact of failing MV repair and MV dysfunction on the right and left atria and on the role of the severity of pulmonary vascular disease. We also do not know whether the major publications discussed truly represent surgical outcomes, as centers with excellent reputations in MV repair do get referrals earlier and probably see less of the significant impact of long-standing MR in their patient populations.

We want to bring attention to another potential modifier on late outcomes. David and colleagues ${ }^{1}$ demonstrated that late recurrence of MR and early TR were associated with late moderate TR. Therefore, it is important to look at the quality of the MV repair, both early and late, in addition to the TV repair, to understand the potential impact on long-term outcome.

In summary, the contribution of McCarthy and colleagues $^{3}$ to the field is significant, as they have highlighted the importance of AF, even when treated effectively and consistently, as a risk factor for recurrent TR.

\section{References}

1. David TE, David CM, Fan CS, Manlhiot C. Tricuspid regurgitation is uncommon after mitral valve repair for degenerative diseases. J Thorac Cardiovasc Surg. 2017; 154:110-22.

2. Chikwe J, Itagaki S, Anyanwu A, Adams DH. Impact of concomitant tricuspid annuloplasty on tricuspid regurgitation, right ventricular function, and pulmonary artery hypertension after repair of mitral valve prolapse. J Am Coll Cardiol. 2015;65: 1931-8.

3. McCarthy PM, Szlapka M, Kruse J, Kislitsina ON, Thomas JD, Liu M, et al. The relationship of atrial fibrillation and tricuspid annular dilation to late tricuspid regurgitation in patients with degenerative mitral repair. J Thorac Cardiovasc Surg. 2021;161:2030-40.e3.

4. McCarthy PM, Bhudia SK, Rajeswaran J, Hoercher KJ, Lytle BW, Cosgrove DM, et al. Tricuspid valve repair: durability and risk factors for failure. $J$ Thorac Cardiovasc Surg. 2004;127:674-85.

5. Badhwar V, Rankin JS, He M, Jacobs JP, Furnary AP, Fazzalari FL, et al. Performing concomitant tricuspid valve repair at the time of mitral valve operations is not associated with increased operative mortality. Ann Thorac Surg. 2017;103:587-94.

6. Dreyfus GD, Corbi PJ, Chan KM, Bahrami T. Secondary tricuspid regurgitation or dilatation: which should be the criteria for surgical repair? Ann Thorac Surg. 2005; 79:127-32

7. Dion RA. Is the air in Toronto, Rochester, and Cleveland different from that in London, Monaco, Leiden, Genk, Milan, and New York? J Thorac Cardiovasc Surg. 2015;150:1040-3.

8. Maghami S, Ghoreishi M, Foster N, Dawood MY, Hobbs GR, Stafford P, et al. Undersized rigid nonplanar annuloplasty: the key to effective and durable repair of functional tricuspid regurgitation. Ann Thorac Surg. 2016;102:735-42.

\title{
Commentary: Gate of success and corridor of failure
}

\author{
Tomasz A. Timek, MD, PhD
}

Functional tricuspid valve regurgitation is a poorly understood entity most frequently associated with left-sided valvular pathology. Although historically little heed was paid to the "forgotten" valve, current surgical guidelines chart a more aggressive course in addressing functional tricuspid insufficiency. ${ }^{1}$ However, there is ample controversy in the literature whether less than moderate tricuspid

From the Division of Cardiothoracic Surgery, Spectrum Health, Michigan State University College of Human Medicine, Grand Rapids, Mich.

Disclosures: Author has nothing to disclose with regard to commercial support.

Received for publication Dec 30, 2019; revisions received Dec 30, 2019; accepted for publication Dec 30, 2019; available ahead of print Jan 22, 2020.

Address for reprints: Tomasz A. Timek, MD, PhD, Division of Cardiothoracic Surgery, Spectrum Health, Michigan State University College of Human Medicine, 100 Michigan Ave NE, Grand Rapids, MI 49503 (E-mail: tomasz.timek@ spectrumhealth.org).

J Thorac Cardiovasc Surg 2021;161:2044-5

$0022-5223 / \$ 36.00$

Copyright (c) 2020 by The American Association for Thoracic Surgery

https://doi.org/10.1016/j.jtcvs.2019.12.107

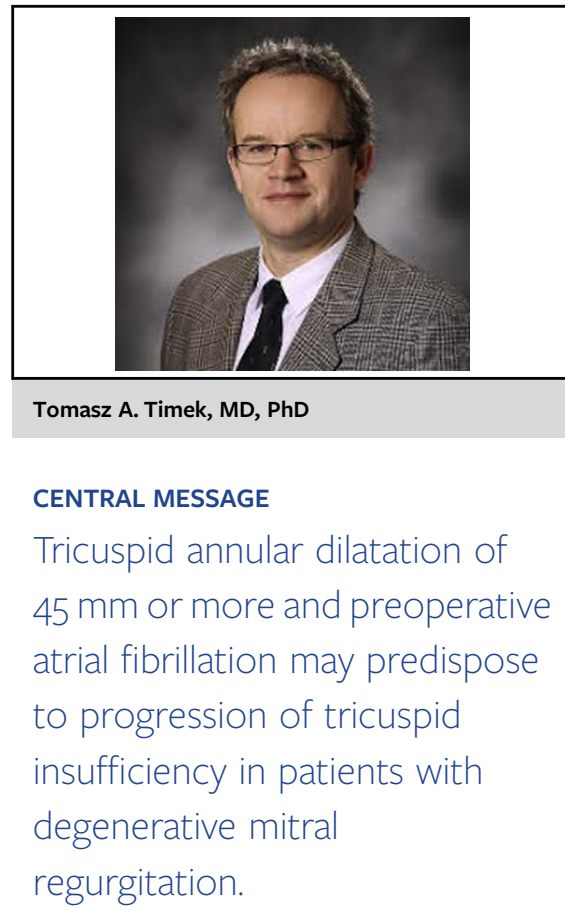

regurgitation (TR) should be treated at the time of left-sided valvular surgery. ${ }^{2,3}$ In the current issue of the Journal, McCarthy and colleagues ${ }^{4}$ from Northwestern University 
present a series of more than 800 patients who underwent mitral valve repair for degenerative disease with less than moderate TR at the time of surgery. Although 97\% underwent a surgical maze procedure, patients with preoperative atrial fibrillation were at higher risk for developing significant late TR, as were those with annular diameter of $45 \mathrm{~mm}$ or more on preoperative echocardiography. Regardless of the present preoperative risk factor, progression to distant functional tricuspid valve regurgitation was associated with increased long-term mortality.

The current report represents one of the largest series in the literature addressing the vexing problem of TR progression after mitral repair, and these results should be carefully considered. Atriogenic functional mitral regurgitation and $\mathrm{TR}^{5,6}$ have been described in the literature, and the physiology of normal atrial valve closure requires atrioventricular synchrony to achieve presystolic annular reduction. ${ }^{7}$ Current data corroborate these prior reports because patients with preoperative atrial fibrillation had a higher rate of annular diameter $45 \mathrm{~mm}$ or greater than those who did not $(20 \%$ vs $3 \%)$. In the absence of atrial fibrillation, the authors discovered that annular diameter of greater than $45 \mathrm{~mm}$ was associated with progressive TR rather than an annular size of $40 \mathrm{~mm}$ recommended by current guidelines. As such, it is not surprising that TR progression was more pronounced in patients with preoperative atrial fibrillation, yet a majority of these patients remained in normal sinus rhythm in the long term because of concomitant surgical ablation. Unfortunately, the authors do not provide data on whether the ablated patients who progressed to TR developed recurrent atrial fibrillation because it would be helpful to elucidate if progression of TR is related to electrical synchrony or whether right-sided ultrastructural changes begotten by severe mitral regurgitation and atrial fibrillation are irreversible regardless of durable mitral repair and ablative therapy. Because annular diameter on follow-up echocardiography was not reported, the link between progressive annular dilatation and distant TR, although plausible, also cannot be firmly established. Last, $43 \%$ of patients $(22 / 51)$ with an annular size of $45 \mathrm{~mm}$ or greater underwent tricuspid annuloplasty at the time of mitral repair, but the outcomes of those patients is not reported or compared with those who were not treated for the same degree of annular dilation.

The study by McCarthy and colleagues ${ }^{4}$ provides further clarity in addressing less than moderate TR at the time of degenerative mitral valve repair. The data suggest prophylactic annular reduction at a diameter of $45 \mathrm{~mm}$ or more or in the presence of preoperative atrial fibrillation. However, these recommendations assume that the etiology of functional tricuspid valve regurgitation is predominantly related to annular pathology, but the exact mechanisms of TR progression remain to be defined.

\section{References}

1. Nishimura RA, Otto CM, Bonow RO. 2014 AHA/ACC guideline for the management of patients with valvular heart disease: a report of the American College of Cardiology/American Heart Association Task Force on Practice Guidelines. J Thorac Cardiovasc Surg. 2014;148:e1-132.

2. David TE, David CM, Manlhiot C. Tricuspid annulus diameter does not predict the development of tricuspid regurgitation after mitral valve repair for mitral regurgitation due to degenerative diseases. J Thorac Cardiovasc Surg. 2018; 155:2429-36.

3. Dreyfus GD, Martin RP, Chan KM, Dulguerov F, Alexandrescu C. Functional tricuspid regurgitation: a need to revise our understanding. J Am Coll Cardiol. 2015;65:2331-6.

4. McCarthy PM, Szlapka M, Kruse J, Kislitsina ON, Thomas JD, Liu M, et al. The relationship of atrial fibrillation and tricuspid annular dilation to late tricuspid regurgitation in degenerative mitral repair patients. J Thorac Cardiovasc Surg. 2021;161:2030-40.e3

5. Muraru D, Guta AC, Ochoa-Jimenez RC, Bartos D, Aruta P, Mihaila S, et al. Functional regurgitation of atrioventricular valves and atrial fibrillation: an elusive pathophysiological link deserving further attention. J Am Soc Echocardiogr. 2020;33:42-53.

6. Utsunomiya H, Itabashi Y, Mihara H, Berdejo J, Kobayashi S, Siegel RJ, et al Functional tricuspid regurgitation caused by chronic atrial fibrillation: a realtime 3-dimensional transesophageal echocardiography study. Circ Cardiovasc Imaging. 2017;10(1).

7. Timek T, Dagum P, Lai DT, Green GR, Glasson JR, Daughters GT, et al. The role of atrial contraction in mitral valve closure. J Heart Valve Dis. 2001;10:312-98. 